\title{
Etiopatogenia e imunoprofilaxia da pneumonia enzoótica suína
}

\author{
Etiopathogenesis and immunoprofilaxis of Swine Enzootic Pneumonia
}

Fabricio Rochedo Conceição ${ }^{1}$ Odir Antônio Dellagostin ${ }^{2}$

- REVISÃO BIBLIOGRÁFICA -

\section{RESUMO}

A Pneumonia Enzoótica Suína (PES), causada pela bactéria fastidiosa Mycoplasma hyopneumoniae, é a doença respiratória mais importante dos suínos, responsável por enormes prejuízos à suinocultura brasileira e mundial. A elevada prevalência e o fato de pré-dispor os suínos à patógenos oportunistas tornam esta doença o alvo central de um programa de saúde de rebanho para doenças respiratórias. O conhecimento das características do agente etiológico bem como dos seus fatores de patogenicidade pode ajudar na elaboração de novas estratégias de controle da PES. O objetivo desta revisão foi discutir alguns aspectos da etiopatogenia da PES que têm implicação na imunoprofilaxia da doença e os principais resultados obtidos com vacinas de última geração avaliadas experimentalmente.

Palavras-chave: Pneumonia Enzoótica Suína, Mycoplasma hyopneumoniae, patogenia, imunoprofilaxia, vacina.

\section{ABSTRACT}

Swine Enzootic Pneumonia (SEP), caused by fastidious bacterium Mycoplasma hyopneumoniae, is the most important respiratory disease of swines, responsible for high losses to Brazilian and worldwide swine breeding. The high prevalence and the fact to predis-pose the swines to secondary pathogens make this disease the central target of a herd health program to respiratory diseases. The knowledge of the characteristics and pathogenicity factors of etiologic agent could help in the development of new strategies to control SEP. The aim of this review was to discuss some aspects of the etiopathogenesis of the SEP that have implications in the immunoprofilaxis of disease and the main results obtained with new generation vaccines evaluated experimentally.

Key words: Swine Enzootic Pneumonia, Mycoplasma hyopneumoniae, pathogenesis, immunoprofilaxis, vaccine.

\section{INTRODUÇÃO}

A suinocultura, no Brasil, é uma atividade organizada, presente em aproximadamente $50 \%$ das propriedades rurais existentes no país. O rebanho suíno brasileiro, estimado em 36,5 milhões de cabeças, tem a sua maior representação numérica, econômica e tecnológica na Região Sul, a qual abriga mais de $42 \%$ do rebanho nacional (IBGE, 2005).

As doenças respiratórias são enfermidades economicamente importantes que afetam a produção suína em todo o mundo. A Pneumonia Enzoótica Suína (PES) ou Pneumonia Micoplásmica Suína, causada pela bactéria fastidiosa Mycoplasma hyopneumoniae, é uma das principais doenças respiratórias dos suínos. M. hyopneumoniae destrói o principal mecanismo de defesa inespecífico do trato respiratório, o elevador mucociliar (DEBEY \& ROSS, 1994), pré-dispondo os suínos a patógenos secundários (CIPRIAN et al., 1988;

${ }^{1}$ Laboratório de Biologia Molecular, Centro de Biotecnologia, Universidade Federal de Pelotas (UFPEL), Caixa Postal 354, 96010-900, Pelotas, RS, Brasil, (53) 3275-7587. E-mail: frochedo@ufpel.tche.br. Autor para correspondência.

${ }^{2}$ Centro de Biotecnologia e Instituto de Biologia, UFPEL, Pelotas, RS, Brasil. 
DEBEY \& ROSS, 1994; THACKER et al., 1999), por isso é o alvo central de um programa de saúde de rebanho para doenças respiratórias. O impacto das doenças respiratórias na suinocultura levou o Ministério da Ciência e Tecnologia a criar o Programa Sul de Análise de Genomas e Biologia Estrutural (Projeto Genoma Sul, http//www.genesul.Incc.br), cujo principal objetivo é o seqüenciamento do genoma dos principais agentes etiológicos de doenças de suínos.

A PES é uma doença infecciosa crônica, muito contagiosa, caracterizada por uma broncopneumonia catarral que geralmente cursa com complicações broncopulmonares purulentas e que se manifesta clinicamente por tosse seca e atraso no crescimento (SOBESTIANSKY et al., 1999). Afeta suínos de todas as idades, porém a forma clínica da doença é mais comum nos animais da fase de crescimento e terminação. A transmissão ocorre por contato direto, indireto e através de aerossóis eliminados durante os acessos de tosse. Variáveis ambientais e de manejo favorecem a sua ocorrência e severidade, por isso é considerada uma doença multifatorial. A PES possui alta morbidade e baixa mortalidade e as perdas econômicas são decorrentes de quedas na produtividade que podem chegar a $20 \%$ sobre a conversão alimentar e até $30 \%$ sobre o ganho de peso, dependendo da gravidade das lesões e das infecções secundárias (SOBESTIANSKY et al., 1999). Um estudo realizado por pesquisadores do Centro Nacional de Pesquisa de Suínos e Aves (CNPSA EMBRAPA, Concórdia, SC, Brasil), onde foram avaliados 3.788 suínos de granjas da região sul do país, revelou que as perdas estimadas de peso devido a lesões pneumônicas, desde o nascimento ao abate, foram de 2,52kg/suíno abatido (SOBESTIANSKY et al., 2001), o que leva a uma estimativa de perda de aproximadamente 80 milhões de reais por ano.

A vacinação parece ser a forma mais efetiva de controlar a PES (KAVANAGH, 1994; LIN et al., 2003). Atualmente, as vacinas contra a PES disponíveis no mercado apresentam um elevado custo de produção e conferem uma proteção parcial, não impedindo o estabelecimento da infecção nem a presença de suínos portadores. O compreendimento das características e dos fatores de patogenicidade da bactéria $\boldsymbol{M}$. hyopneumoniae pode ajudar no desenvolvimento de novas estratégias de controle da PES, principalmente na imunoprofilaxia. O objetivo desta revisão foi discutir alguns aspectos da etiopatogenia da PES que têm implicação na imunoprofilaxia da doença e também os principais resultados obtidos com vacinas de última geração avaliadas experimentalmente.

\section{Etiopatogenia}

Os micoplasmas são diferenciados fenotipicamente de outras bactérias pelo diminuto tamanho e ausência de parede celular. Pertencem à classe Mollicutes (mollis, mole; cutis, pele, em Latim), composta pelos gêneros Acholeplasma, Anaeroplasma, Asteroplasma, Mycoplasma, Spiroplasma e Ureaplasma, ordem Mycoplasmatales, família Mycoplasmataceae e gênero Mycoplasma (WALKER, 2003). A maioria dos membros desta classe é patogênica e coloniza uma grande variedade de hospedeiros, incluindo animais, plantas e insetos. Somente os membros do gênero Mycoplasma e Ureaplasma são importantes na medicina veterinária. Os micoplasmas são os menores organismos autoreplicantes conhecidos, possuem genomas pequenos (580 a $1350 \mathrm{~kb}$ ), com baixo conteúdo de guanina + citosina (23-40\%) e são filogeneticamente relacionados aos gêneros Clostridium, Streptococcus e Lactobacillus (MANILOFF, 1992). A morfologia dos micoplasmas é bastante pleomórfica em função da ausência da parede celular. A célula pode ser esférica, em forma de pêra, em forma de espiral ou filamentosa. O diâmetro da forma esférica varia de 0,3 a $0,8 \mu \mathrm{m}$. Coramse de forma insatisfatória pelo método de Gram, sendo recomendado as colorações Giemsa, Castañeda, Dienes e novo azul de metileno. Possuem uma membrana trilaminar simples composta de proteínas, glicoproteínas, glicolipídeos, fosfolipídeos e colesterol, este último responsável pela rigidez e estabilidade osmótica da membrana. Os micoplasmas crescem lentamente em meio de cultivo após incubação de 3 a 20 dias, a uma temperatura ótima de $37^{\circ} \mathrm{C}$, $\mathrm{pH}$ em torno de 7.5 , atmosfera de 5 a $10 \%$ de $\mathrm{CO}_{2}$ e leve agitação (WALKER, 2003).

A ausência da parede celular torna os micoplasmas resistentes aos antimicrobianos que afetam a sua síntese, como penicilinas, cefalosporinas, bacitracina, entre outros e também favorece a passagem destes microorganismos por membranas de $0,22 \mu \mathrm{m}$. $\boldsymbol{M}$. hyopneumoniae é inativado em 48 horas por dessecação, porém pode persistir por 17 dias em água de chuva entre 2 a $7^{\circ} \mathrm{C}$ e de 3 a 7 dias no tecido pulmonar entre 17 a $25^{\circ} \mathrm{C}$ (SOBESTIANSKY et al., 1999).

Micoplasmas são de difícil cultivo “in vitro”, sendo que a maioria das espécies nunca foi cultivada (RAZIN et al., 1998). M. hyopneumoniae, por outro lado, é cultivável “in vitro”, porém exige meio enriquecido. Este fato, somado ao seu crescimento pobre e lento (ROSS, 1999; SOBESTIANSKY et al., 1999; WALKER, 2003), encarece excessivamente a produção de vacinas preparadas com bactérias inteiras inativadas (bacterinas), que são as mais utilizadas no 
controle da PES (ROSS, 1999; FAGAN et al., 1997; CHEN et al., 2001). M. hyopneumoniae geralmente é cultivado em meio Friis (FRIIS, 1975), o meio de cultivo mais utilizado para micoplasmas. No cultivo primário, o crescimento produz uma turbidez discreta e uma coloração ácida em 3 a 20 dias. Após a adaptação em caldo (no mínimo quatro passagens), o cultivo é transferido para meio sólido e incubado em estufa a $37^{\circ} \mathrm{C}$, com atmosfera de 5 a $10 \%$ de $\mathrm{CO}_{2}$. As colônias tornam-se visíveis após 2 a 3 dias de incubação, porém o mais comum é observá-las após 10 dias, quando estão com aproximadamente 0,25 a $1 \mathrm{~mm}$ de diâmetro (ROSS, 1999). A necessidade de enriquecer o meio Friis com soro suíno livre de anticorpos anti - $M$. hyopneumoniae encarece mais ainda o cultivo deste patógeno. Para cada litro de meio Friis, são necessários $200 \mathrm{ml}$ de soro de suíno SPF (specific pathogen free), cujo custo é de aproximadamente U\$ 50 (SIGMA, 2005).

Ao contrário de micoplasmas patogênicos para o homem (M. genitalium e M. pneumoniae), que são intracelulares, M. hyopneumoniae é um microorganismo de vida livre. Porém, o isolamento deste microorganismo é complicado devido a sua natureza fastidiosa e também pela freqüente presença no trato respiratório suíno de $\boldsymbol{M}$. hyorhinis, causador de poliserosites e artrites e $\boldsymbol{M}$. flocculare, espécie não patogênica que apresenta semelhanças ao $\boldsymbol{M}$. hyopneumoniae em relação à morfologia, crescimento e antigenicidade (ROSS, 1999).

Os recentes projetos genomas encontraram explicações genéticas para os problemas mencionados acima, demonstrando uma notável escassez em micoplasmas de genes envolvidos em rotas biosintéticas. Por exemplo, M. genitalium e $\boldsymbol{M}$. pneumoniae não possuem os genes envolvidos na biosíntese de aminoácidos (FRASER et al., 1995; HIMMELREICH et al., 1996), tornando-os totalmente dependentes de suplemento exógeno. Além disso, todos os micoplasmas necessitam de colesterol para o seu crescimento (RAZIN et al., 1998). De um total de 692 prováveis seqüências codificadoras de proteínas, identificadas após o seqüenciamento da cepa 232 de M. hyopneumoniae (MINION et al., 2004), foram identificadas apenas 16 seqüências (2,2\%) envolvidas na biosíntese de moléculas: três para a biosíntese de aminoácidos, oito para cofatores, grupos prostéticos ou carreadores, duas para poliaminas e três para açúcares, sugerindo que este microorganismo também apresenta uma limitada capacidade de biosíntese.

Recentemente, a seqüência do genoma da cepa patogênica 232 de $\boldsymbol{M}$. hyopneumoniae foi publicada (MINION et al., 2004), destacando-se as seguintes características gerais: o genoma consiste de
892,758 pb; o conteúdo total de G + C é 28,6\%; das 692 prováveis seqüências codificadoras de proteínas, funções foram assinaladas para 304 (44\%), enquanto 261 (38\%) seqüências são de proteínas hipotéticas conservadas e 127 (18\%) codificam proteínas hipotéticas exclusivas deste patógeno; o genoma contém um operon para rRNA 16S-23S, uma seqüência codificadora para rRNA 5S e trinta seqüências codificadoras para tRNA. Um padrão incomum de códon preferencial foi encontrado, sugerindo uma possível aquisição de genes por transferência horizontal. Processamento incompleto de lipoproteínas, incapacidade de modificar fosfolipídeos, sistema simplificado de secreção de proteínas de membrana, ausência de um gene para a RNase H (responsável pela remoção dos fragmentos de Okasaki), ausência das proteínas GroEL e GroES (proteínas altamente conservadas em eubactérias), sistema primitivo de resposta ao stress e reparo de DNA, presença de um único fator sigma e de seis parálogos do gene para a adesina ciliar P97 são outras características relevantes do genoma de $\boldsymbol{M}$. hyopneumoniae que ajudam a compreender um pouco mais sobre a fisiologia e evolução deste importante patógeno. Filogeneticamente, entre as outras nove espécies de micoplasmas já seqüenciadas, $\boldsymbol{M}$. hyopneumoniae está mais relacionado à $\boldsymbol{M}$. pulmonis, um patógeno de roedores (MINION et al., 2004).

Assim como a maioria dos membros da ordem Mycoplasmatales, $\boldsymbol{M}$. hyopneumoniae infecta uma única espécie, a suína, porém os mecanismos de especificidade pelo hospedeiro ainda são desconhecidos. Uma notável característica da PES é a cronicidade, porém igualmente importante é a habilidade que $\boldsymbol{M}$. hyopneumoniae possui de alterar ou desviar a resposta imune e pré-dispor o suíno a infecções secundárias (CIPRIAN et al., 1988; DEBEY \& ROSS, 1994; THACKER et al., 1999).

Uma característica muito importante de micoplasmas, com potencial patogênico e implicações no controle, é a notável capacidade de alterar os seus antígenos de superfície. Com isso, estes microorganismos conseguem evadir a resposta imune montada pelo hospedeiro e estabelecer uma infecção crônica. Algumas espécies de micoplasmas patogênicos, como $\boldsymbol{M}$. hyorhinis, $\boldsymbol{M}$. bovis e $\boldsymbol{M}$. gallisepticum possuem uma sofisticada maquinaria genética para alterar os seus antígenos de superfície através de mecanismos como variação de fase, variação de tamanho e mascaramento/desmascaramento de epítopos de proteínas de superfície (RAZIN et al., 1998). A variação antigênica em micoplasmas geralmente está relacionada à presença de seqüências de DNA 
repetitivas nos genes. Provavelmente, durante o processo de replicação do DNA, é que ocorre a mudança no número de unidades repetitivas responsável pela variação antigênica (DJORDJEVIC et al., 2004). Curiosamente, ao contrário de outros micoplasmas, $\boldsymbol{M}$. hyopneumoniae contém poucos genes com seqüências repetitivas que poderiam estar envolvidas na variação antigênica (MINION et al., 2004). Desta forma, ainda não está claro como este microorganismo evade o sistema imune e estabelece uma infecção crônica. Recentemente, DJORDJEVIC et al. (2004) demonstraram que a adesina P97 de $\boldsymbol{M}$. hyopneumoniae é seletivamente clivada após a sua tradução, gerando subprodutos com diferentes tamanhos. A habilidade de $\boldsymbol{M}$. hyopneumoniae clivar seletivamente as suas proteínas secretadas sugere que este microorganismo também possui capacidade de alterar a sua arquitetura de superfície.

Heterogeneidade entre cepas de $\boldsymbol{M}$. hyopneumoniae foi observada através de teste de inibição do metabolismo, digestão com enzimas de restrição, PCR, perfil total de proteínas e perfil de glicoproteínas (DESROSIERS, 2001). VICCA et al. (2003) encontraram uma alta variação na virulência de cepas de $\boldsymbol{M}$. hyopneumoniae isoladas em diferentes rebanhos. As cepas de moderada ou alta virulência apresentaram uma banda de 5000 pb, determinada através de randomly amplified polymorphic DNA (RAPD), que estava ausente nas cepas de baixa virulência.

A caracterização antigênica de cepas de determinados patógenos é essencial para a seleção de antígenos vacinais adequados e deve ser realizada periodicamente, tendo em vista a constante mudança no perfil antigênico das cepas prevalentes (CONCEIÇÃO \& TURNES, 2003; CONCEIÇÃO et al., 2003a). Trabalhos visando à caracterização antigênica de cepas de $\boldsymbol{M}$. hyopneumoniae são escassos e dificultados pela natureza fastidiosa do microorganismo. Recentemente, foi proposta a análise comparativa dos genomas de diferentes isolados de M. hyopneumoniae, visando a buscar através da genômica a detecção de uma possível diversidade antigênica existente entre estes isolados (ZAHA, 2004 - Informe Verbal).

Micoplasmas patogênicos utilizam um mecanismo de patogenicidade bastante complexo; este envolve a adesão/colonização, citotoxicidade, competição por substratos, evasão e ou modulação da resposta imune do hospedeiro, efeito clastogênico e oncogênico (RAZIN et al., 1998; ROSS, 1999). Entretanto, a base molecular da patogenicidade de alguns micoplasmas ainda permanece obscura.
Infecções em humanos e animais causadas por micoplasmas sugerem que o dano provocado nesses hospedeiros se deve à resposta imune e inflamatória montada em vez de ao efeito tóxico direto causado pelos componentes celulares destes microorganismos (RAZIN et al., 1998). Após o seqüenciamento da cepa patogênica 232 de $\boldsymbol{M}$. hyopneumoniae, foram identificados 8 genes para proteases, 53 genes para lipoproteínas (8,5\% do genoma) e 6 genes homólogos à adesina $\mathrm{P} 97$ que poderiam contribuir para a persistência e virulência do agente (MINION et al., 2004). Proteases estão ligadas à virulência de bactérias Gram positivas (TORTORA et al., 2000), sendo que uma ou mais delas poderiam estar envolvidas no processamento pós-traducional da adesina P97 (DJORDJEVIC et al., 2004), um fator de patogenicidade de $\boldsymbol{M}$. hyopneumoniae bem caracterizado. Lipoproteínas, que são os principais componentes de membrana de micoplasmas, compreendem aproximadamente $2 / 3$ da massa total da membrana (RAZIN et al., 1998) e são elas que normalmente sofrem uma variação antigênica frente à resposta imune do hospedeiro. Por outro lado, a função dos genes homólogos à adesina P97 é desconhecida e provavelmente não está relacionada com a adesão, uma vez que apenas um deles possui o domínio repetitivo R1 responsável pela ligação ao receptor ciliar (MINION et al., 2000; MINION et al., 2004).

Cepas de $\boldsymbol{M}$. hyopneumoniae com baixa capacidade de aderência ao cílio suíno não são patogênicas (ZIELINSKI \& ROSS, 1993). Com a exceção da adesina ciliar P97, fatores de patogenicidade não têm sido claramente estabelecidos em $\boldsymbol{M}$. hyopneumoniae. O evento inicial na patogenia da PES é a adesão/colonização de $\boldsymbol{M}$. hyopneumoniae no trato respiratório suíno. A adesina P97, identificada por ZHANG et al. (1995), reconhece receptores glicolipídicos sulfatados presentes nos cílios das células epiteliais do trato respiratório suíno (ZHANG et al., 1994). HSU \& MINION (1998) identificaram o epítopo da P97 que é responsável pela ligação ao receptor ciliar, uma seqüência repetitiva de cinco aminoácidos (AAKPV/E) que é altamente imunogênica e que está localizada na porção C terminal da proteína, designada região R1. Cepas de $\boldsymbol{M}$. hyopneumoniae com variação no número de repetições da região R1 (8 a 15) foram identificadas (WILTON et al., 1998), sugerindo que esta variação poderia influenciar a capacidade de ligação ao cílio suíno. Porém, MINION et al. (2000), utilizando fusões de $\beta$-galactosidase com diferentes números de repetições $\mathrm{R} 1$, concluíram que no mínimo oito repetições são requeridas para a ligação ao cílio suíno e três para o reconhecimento dos MAbs 
F1B6 e F2G5. Estes MAbs bloquearam a aderência de M. hyopneumoniae ao cílio suíno em um teste de inibição da aderência "in vitro" (ZHANG et al., 1995), sugerindo que a região R1 da adesina P97 possui papel fundamental na patogenia da PES, tornando-a uma forte candidata a antígeno vacinal. O gene que codifica a adesina P97 ( $p 97$ ) foi clonado e seqüenciado (HSU et al., 1997). A análise deste gene revelou uma open reading frame (ORF) que codifica para uma proteína de $125 \mathrm{kDa}$, a qual apresenta um domínio transmembrana hidrofóbico e um peptídeo sinal. A clivagem pós-traducional do peptídeo sinal produz uma proteína de aproximadamente $102,3 \mathrm{kDa}$, que migra em SDS-PAGE até $97 \mathrm{kDa}$, por isso foi designada P97 (ZHANG et al., 1995). O gene $p 97$ encontra-se em um operon juntamente com outro gene que codifica para uma proteína de $102 \mathrm{kDa}$, cuja função é desconhecida (MINION et al., 2004). Provavelmente, devido à localização, esta proteína participe direta ou indiretamente da adesão.

A expressão da P97 e a presença de um número adequado de repetições R1 não são suficientes para conferir capacidade de aderência, uma vez que a cepa J de M. hyopneumoniae, uma cepa pouco aderente e não patogênica, expressou uma adesina funcional com nove repetições $R 1$, sugerindo que fatores ou proteínas adicionais também são requeridos para a aderência ao cílio suíno (HSU \& MINION, 1998). Estes fatores poderiam participar da modificação póstraducional da P97, da sua translocação ou da sua substituição na membrana. CHEN et al. (1998) identificaram uma glicoproteína de 110 kDa que também apresentou capacidade de ligação ao cílio suíno. Enfim, o processo de adesão/colonização utilizado por $\boldsymbol{M}$. hyopneumoniae é complexo e a sua elucidação poderia ajudar no desenvolvimento de novas alternativas de controle da PES.

Após aderir-se aos cílios da traquéia, brônquios e bronquíolos, M. hyopneumoniae inicialmente paralisa e depois destrói estas estruturas (DEBEY \& ROSS, 1994), pré-dispondo os suínos a infecções secundárias. M. hyopneumoniae interage com macrófagos alveolares e linfócitos, estimulandoos a produzir citocinas pró-inflamatórias (TNF- $\alpha$, IL-1 e IL-6) responsáveis pelas lesões pulmonares e pela hiperplasia linfóide perivascular e peribrônquica (RODRÍGUEZ et al., 2004) características da PES, sugerindo o envolvimento da resposta imune no desenvolvimento das lesões. Além disso, micoplasmas são capazes de ativar a mitose de linfócitos B e T (RAZIN et al., 1998), o que também poderia auxiliar na evolução da hiperplasia linfóide. O avanço da hiperplasia resulta na obstrução das vias aéreas levando à formação de lesões atelectásicas nos pulmões, as quais apresentam aspecto de consolidação e coloração que varia do roxo ao cinza, localizadas principalmente na região cranioventral dos lobos apicais e cardíacos (SOBESTIANSKY et al., 1999).

Além da adesão/colonização e interação com o sistema imune, outros aspectos da patogenia da PES vêm sendo identificados. Recentemente, SCHMIDT et al. (2004) identificaram em $\boldsymbol{M}$. hyopneumoniae uma lipoproteína de superfície imunodominante (P65) que é especificamente reconhecida durante a infecção. A P65 pertence à família de enzimas lipolíticas GDSL e, embora a sua função fisiológica e ou patogênica ainda não tenha sido elucidada, ela pode desempenhar uma importante função nutricional, sendo responsável pela aquisição de ácidos graxos de cadeia longa e também pode reduzir a função de surfactantes pulmonares, favorecendo a atelectasia dos alvéolos. Soro de coelho anti-P65 inibiu o crescimento "in vitro" de $\boldsymbol{M}$. hyopneumoniae, sugerindo que este antígeno possui potencial imunoprofilático. Superóxido dismutase $\mathrm{Cu} /$ Zn (SODCu/Zn) é uma enzima chave na defesa contra os reativos intermediários de oxigênio. Esta enzima é encontrada em eucariotos e várias espécies de bactérias Gram negativas. CHEN et al. (2000) identificaram em $\boldsymbol{M}$. hyopneumoniae uma proteína de aproximadamente $17 \mathrm{kDa}$, com atividade de SODCu/Zn, que poderia minimizar os efeitos da resposta inflamatória sobre o patógeno. No Projeto Genoma Sul foram seqüenciadas as cepas 7448 (patogênica) e J (não patogênica) de $\boldsymbol{M}$. hyopneumoniae. A análise comparativa dos genomas revelou a existência de um provável elemento conjugativo integrativo (ECI) presente apenas na cepa patogênica. Uma hipótese, a qual necessita ainda ser confirmada, é que este ECI seja responsável pela transferência de moléculas efetoras de $\boldsymbol{M}$. hyopneumoniae para as células epiteliais do trato respiratório (ZAHA, 2004 - Informe verbal). Uma análise proteômica destas cepas também poderia ajudar no compreendimento dos fatores de patogenicidade de $\boldsymbol{M}$. hyopneumoniae e, por conseguinte, no desenvolvimento de medidas de controle mais eficientes.

Imunoprofilaxia

As únicas vacinas contra a PES disponíveis no mercado são as bacterinas. Elas conferem proteção aos suínos, caracterizada esta pela redução das lesões e melhora dos índices de produtividade (ganho de peso e conversão alimentar), porém não impedem a colonização de $\boldsymbol{M}$. hyopneumoniae nem o estabelecimento de suínos portadores, uma vez que este tipo de vacina não estimula uma adequada 
imunidade de mucosa (IgAs). Apesar disso, reduzem de forma significativa o impacto econômico da PES (MAES et al., 1999; MOREAU et al., 2004).

As bacterinas contra a PES apresentam um elevado custo de produção (FAGAN et al., 1997; CHEN et al., 2001) devido às dificuldades no cultivo de $\boldsymbol{M}$. hyopneumoniae, por isso o desenvolvimento de novas vacinas contra esta doença torna-se atrativo e necessário. As bacterinas constituem o medicamento mais oneroso no custo de produção de suínos, representando aproximadamente um centavo de real/ Kg de peso vivo (http://www.suíno.com.br/estatisticas/, acessado em 02/2005). Nesse contexto, a produção de vacinas através da tecnologia do DNA recombinante destaca-se, uma vez que o cultivo do agente em larga escala não é necessário. Porém, a expressão de genes de micoplasmas em outros organismos (E. coli, outros vetores bacterianos, leveduras, plantas e células eucarióticas) é dificultada pelo fato de que micoplasmas utilizam o códon UGA para codificar triptofano, enquanto que, nos outros organismos, este códon é reconhecido como um "stop” códon. Assim sendo, nestes organismos, a tradução de um mRNA de um gene de micoplasma vai ser interrompida em locais onde deveria ser incorporado um triptofano, resultando em proteínas truncadas (RAZIN et al., 1998). A produção de mutações sítio específicas no sentido de alterar os códons TGA por TGG, um códon padrão para triptofano em outros organismos, tem sido a estratégia utilizada para contornar este problema (CHUNG et al., 2000; ROSATI et al., 2000; NOH et al., 2002).

Algumas vacinas de última geração contra a PES foram desenvolvidas e avaliadas experimentalmente. Uma discussão dos principais resultados obtidos com estas vacinas será descrita a seguir. Uma vacina produzida a partir de sobrenadante de cultura de $\boldsymbol{M}$. hyopneumoniae reduziu significativamente as lesões pulmonares de suínos vacinados/desafiados (OKADA et al., 2000), contribuindo para a redução da produção de TNF- $\alpha$, uma citocina pró-inflamatória envolvida no desenvolvimento das lesões características da PES. Contudo, este tipo de vacina também apresenta elevado custo de produção, uma vez que o cultivo de $\boldsymbol{M}$. hyopneumoniae é necessário. FAGAN et al. (1996) avaliaram por via intramuscular (I.M.) uma vacina de subunidade recombinante composta por um fragmento da subunidade R2 da ribonucleotídeo redutase de $\boldsymbol{M}$. hyopneumoniae ( $\mathrm{NrdF}$ ), fusionada a $\beta$-galactosidase. Esta vacina reduziu significativamente as lesões pulmonares de suínos vacinados/desafiados, porém não impediu o estabelecimento da infecção. Por outro lado, uma vacina de subunidade recombinante composta pela adesina P97 não conferiu proteção contra a PES. Na opinião dos autores do presente artigo, a possível falha na proteção ocorreu devido à via de administração utilizada (IM), uma vez que a administração parenteral de imunógenos não induz uma adequada imunidade de mucosa (MCGHEE et al., 1992). THACKER et al. (2000) e LIN et al. (2003) sugeriram que anticorpos de mucosa (IgA) são importantes para o controle da PES. Uma bacterina de $\boldsymbol{M}$. hyopneumoniae microencapsulada, administrada por via oral, conferiu proteção efetiva contra a PES (LIN et al., 2003). A administração oral de antígenos encapsulados com microesferas evita a degradação no estômago e possibilita a estimulação do sistema imune da mucosa intestinal (Placas de Peyer). Após a estimulação, as células imunocompetentes migram para outros sítios do organismo, como as mucosas respiratória e urogenital e glândulas mamária, lacrimal e salivar.

FAGAN et al. (2001) avaliaram uma vacina composta por uma Salmonella typhimurium atenuada (aroA), expressando um fragmento da NrdF de $\boldsymbol{M}$. hyopneumoniae. A imunização oral de suínos com esta vacina estimulou significativamente a produção de IgA secretora anti-NrdF no trato respiratório suíno e reduziu as lesões pulmonares de suínos vacinados/desafiados. SHIMOJI et al. (2003) avaliaram a eficácia de uma vacina composta por uma cepa atenuada de Erysipelothrix rhusiopathiae (YS-19), expressando a região C terminal da adesina P97 de M. hyopneumoniae. Suínos imunizados com YS-19 por via intranasal (I.N.) apresentaram uma redução significativa das lesões pulmonares após o desafio, porém anticorpos séricos anti-P97 e imunidade celular não foram detectados, indicando um mecanismo de proteção desconhecido. Os resultados sugerem que a proteção conferida por esta vacina resultou de uma competição entre a cepa YS-19 e M. hyopneumoniae pelos receptores ciliares do trato respiratório suíno, uma vez que a cepa YS-19 expressa na sua superfície a região C terminal da P97, que possui o epítopo de ligação ao cílio suíno (região R1). Em um trabalho do mesmo grupo (SHIMOJI et al., 2002), não foi detectada uma produção significativa de IgA anti-P97 no trato respiratório de suínos imunizados com a cepa YS-19.

O soro de camundongos imunizados com uma vacina de DNA composta pelo plasmídeo pcDNA3 carreando o gene da proteína de choque térmico P42 inibiu o crescimento "in vitro” de $\boldsymbol{M}$. hyopneumoniae, sugerindo que a vacinação genética constitui uma nova estratégia contra a PES (CHEN et al., 2003). CHEN et al. (2001) fusionaram a região R1 da adesina P97 de $\boldsymbol{M}$. hyopneumoniae com a exotoxina A, domínio III 
deletado, de Pseudomonas [PE( $\Delta \mathrm{III})]$. Camundongos e suínos imunizados com a PE( $\Delta$ III)-R1 apresentaram uma elevada produção de IgG sérica anti-R1, entretanto, a resposta imune de mucosa (IgAs) contra este antígeno, a qual nós acreditamos ser protetora, não foi determinada. CONCEIÇÃO et al. (2003b) desenvolveram uma vacina de subunidade recombinante (rLTB-R1) composta pela região R1 da adesina P97 de $\boldsymbol{M}$. hyopneumoniae (R1) fusionada à subunidade B da enterotoxina termolábel de $\boldsymbol{E}$. coli (LTB), um potente adjuvante de mucosa (SIMMONS et al., 2001). Camundongos imunizados com rLTB-R1, por via IM ou IN, produziram altos níveis de IgA antiR1 no trato respiratório (dados não publicados), demonstrando o potencial desta vacina. É possível que altos níveis de IgA anti-R1 no trato respiratório suíno possam bloquear a colonização de M. hyopneumoniae.

\section{CONCLUSÃO}

Os recentes projetos genoma de $\boldsymbol{M}$. hyopneumoniae identificaram novas proteínas com potencial imunoprofilático e também ajudaram a compreender um pouco mais sobre a fisiologia e patogenia deste microorganismo. Atualmente, as bacterinas contra a Pneumonia Enzoótica Suína disponíveis no mercado não protegem suficientemente contra a infecção. Novas vacinas contra esta doença vêm sendo desenvolvidas, destacando-se aquelas que estimulam a produção de IgA na mucosa respiratória suína.

\section{INFORME VERBAL}

ARNALDO ZAHA. Centro de Biotecnologia, Universidade Federal do Rio Grande do Sul, Av. Bento Gonçalves, 9500, prédio 43421, Caixa Postal 15005, 91501970, Porto Alegre, RS, Brasil. Fone: (51) 316-6054. E-mail: zaha@dna.cbiot.ufrgs.br - Informação obtida durante uma palestra proferida no Curso de Seqüenciamento e Análise de Genomas II, realizado no CenBiot - UFRGS em novembro de 2004.

\section{REFERÊNCIAS}

CHEN, J.R. et al. Identification of a novel adhesion-like glycoprotein from Mycoplasma hyopneumoniae. Veterinary Microbiology, v.62, p.97-110, 1998.

CHEN, J.R. et al. Identification of the copper-zinc superoxide dismutase activity in Mycoplasma hyopneumoniae. Veterinary Microbiology, v.73, p.301-310, 2000.

CHEN, J.R. et al. A recombinant chimera composed of repeat region RR1 of Mycoplasma hyopneumoniae adhesin with Pseudomonas exotoxin: in vivo evaluation of specific IgG response in mice and pigs. Veterinary Microbiology, v.80, p.347-357, 2001.

CHEN, Y.L. et al. Expression and immunogenicity of Mycoplasma hyopneumoniae heat shock protein antigen $\mathrm{P} 42$ by DNA vaccination. Infection and Immunity, v.71, p.11551160, 2003.

CHUNG, T. et al. Molecular cloning and characterization of a unique $60 \mathrm{kDa} / 72 \mathrm{kDa}$ antigen gene encoding enzyme I of the phosphoenolpyruvate: sugar phosphotransferase system (PTS) of Mycoplasma hyopneumoniae. Journal of Biochemistry, v.128, p.261-269, 2000.

CONCEIÇÃO, F.R.; TURNES, G.C. Moraxella bovis: influência das características genotípicas e fenotípicas no controle da ceratoconjuntivite infecciosa bovina. Ciência Rural, v.33, p.778-787, 2003.

CONCEIÇÃO, F.R. et al. Antigenic relationships of Moraxella bovis strains recovered from outbreaks of infectious bovine keratoconjunctivitis in Argentine, Brazil and Uruguay between 1983 and 2000. Canadian Journal of Veterinary Research, v.67, p.315-318, 2003a.

CONCEIÇÃO, F.R. et al. LTB-R1: an alternative to swine mycoplasmal pneumonia control. Brazilian Journal of Microbiology, v.34, supl.1, p.79-81, 2003 b.

CIPRIAN, A. et al. Mycoplasma hyopneumoniae increases the susceptibility of pigs to experimental Pasteurella multocida pneumonia. Canadian Journal of Veterinary Research, v.52, p.434-438, 1988.

DEBEY, M.C., ROSS, R.F. Ciliostasis and loss of cilia induced by Mycoplasma hyopneumoniae in porcine tracheal organ cultures. Infection and Immunity, v.62, p.5312-5318, 1994.

DESROSIERS, R. A review of some aspects of the epidemiology, diagnosis, and control of Mycoplasma hyopneumoniae infections. Journal of Swine Health and Production, v.9, p.233-237, 2001.

DJORDJEVIC, S.P. et al. Proteolytic processing of the Mycoplasma hyopneumoniae cilium adhesin. Infection and Immunity, v.72, p.2791-2802, 2004.

FAGAN, P.K. et al. Molecular characterization of a ribonucleotide redutase ( $n r d F)$ gene fragment of Mycoplasma hyopneumoniae and assessment of the recombinant product as an experimental vaccine for enzootic pneumonia. Infection and Immunity, v.64, p.1060-1064, 1996.

FAGAN, P.K. et al. Oral immunization of mice with attenuated Salmonella typhimurium aroA expressing a recombinant Mycoplasma hyopneumoniae antigen (NrdF). Infection and Immunity, v.65, p.2502-2507, 1997.

FAGAN, P.K. et al. Oral immunization of swine with attenuated Salmonella typhimurium aroA SL3261 expressing a recombinant antigen of Mycoplasma hyopneumoniae (NrdF) 
primes the immune system for a NrdF specific secretory IgA response in the lungs. Microbial Pathogenesis, v.30, p.101110, 2001.

FRASER, C.M. et al. The minimal gene complement of Mycoplasma genitalium. Science, v.270, p.397-403, 1995.

FRIIS, N.F. Some recommendations concerning primary isolation of Mycoplasma suipneumoniae and Mycoplasma flocculare: a survey. Nord Veterinary Medicine, v.27, p.337339, 1975.

HIMMELREICH, R. et al. Complete sequence analysis of the genome of the bacterium Mycoplasma pneumoniae. Nucleic Acids Research, v.24, p.4420-4449, 1996.

HSU, T.; MINION, F.C. Identification of the cilium binding epitope of the Mycoplasma hyopneumoniae P97 adhesin. Infection and Immunity, v.66, p.4762-4766, 1998

HSU, T. et al. Cloning and functional analysis of the P97 swine cilium adhesin gene of Mycoplasma hyopneumoniae. Journal of Bacteriology, v.179, p.1317-1323, 1997.

IBGE - Instituto Brasileiro de Geografia e Estatística. 2005. Capturado em 10 fev. 2005. On line. Disponível na Internet http://www.ibge.gov.br

KAVANAGH, N.T. The effect of pulse medication with combination of tiamulin and oxytetracycline on the performance of fattening pigs in a herd infected with enzootic pneumonia. International Veterinary Journal, v.47, p.58$61,1994$.

LIN, J.H. et al. Protective effects of oral microencapsuled Mycoplasma hyopneumoniae vaccine prepared by co-spray drying method. Journal of Veterinary Medicine Science, v.65, p.69-74, 2003.

MAES, D. et al. Effect of vaccination against Mycoplasma hyopneumoniae in pig herds with an all-in/all-out production system. Vaccine, v.17, p.1024-1034, 1999.

MANILOFF, J. Phylogeny of mycoplasmas. In: Mycoplasmas: molecular biology and pathogenesis. Washington, DC: American Society for Microbiology, 1992. p.549-559.

McGHEE, J.R. et al. The mucosal immune system: from fundamental concepts to vaccine development. Vaccine, v.10, p.75-88, 1992 .

MINION, F.C. et al. R1 region of P97 mediates adherence of Mycoplasma hyopneumoniae to swine cilia. Infection and Immunity, v.68, p.3056-3060, 2000

MINION, F.C. et al. The genome sequence of Mycoplasma hyopneumoniae strain 232, the agent of swine mycoplasmosis. Journal of Bacteriology, v.186, p.7123-7133, 2004.

MOREAU, I.A. et al. Effects of Mycoplasma hyopneumoniae vaccine on pigs naturally infected with M. hyopneumoniae and porcine reproductive and respiratory syndrome virus. Vaccine, v.22, p.2328-2333, 2004

$\mathrm{NOH}$, E.J. et al. Characterization of mycoplasma arginine deiminase expressed in $\boldsymbol{E}$. coli and its inhibitory regulation of nitric oxide synthesis. Molecular Cells, v.13, p.137-143, 2002.

OKADA, M. et al. Cytological and immunological changes in bronchoalveolar lavage fluid and histological observation of lung lesions in pigs immunized with Mycoplasma hyopneumoniae inactivated vaccine prepared from broth culture supernate. Vaccine, v.18, p.2825-2831, 2000.

RAZIN, S. et al. Molecular biology and pathogenicity of mycoplasmas. Microbiology and Molecular Biology Reviews, v.62, p.1094-1156, 1998.

RODRÍGUEZ, F. et al. Immunohistochemical Labelling of Cytokines in Lung Lesions of Pigs Naturally Infected with Mycoplasma hyopneumoniae. Journal of Comparative Pathology, v.130, p.306-312, 2004.

ROSATI, S. et al. Expression and antigenic characterization of recombinant Mycoplasma agalactiae P48 major surface protein. Veterinary Microbiology, v.71, p.201-210, 2000.

ROSS, R.F. Mycoplasmal diseases. In: STRAW, B.E. et al. Diseases of swine. 8.ed. Ames, Iowa: Iowa State University, 1999. p.495-510

SCHMIDT, J.A. et al. Mycoplasma hyopneumoniae p65 Surface Lipoprotein Is a Lipolytic Enzyme with a Preference for Shorter-Chain Fatty Acids. Journal of Bacteriology, v.186, p.5790-5798, 2004.

SHIMOJI, Y. et al. Erysipelothrix rhusiopathiae YS-1 as a live vaccine vehicle for heterologous protein expression and intranasal immunization of pigs. Infection and Immunity, v.70, p.226-232, 2002.

SHIMOJI, Y. et al. Vaccine efficacy of the attenuated Erysipelothrix rhusiopathiae YS-19 expressing a recombinant protein of Mycoplasma hyopneumoniae P97 adhesin against mycoplasmal pneumonia of swine. Vaccine, v.21, p.532-537, 2003.

SIGMA. 2005. Capturado em 16 fev. 2005. Online. Disponível na Internet http://www.sigma-aldrich.com

SIMMONS, C.P. et al. Immunomodulation using bacterial enterotoxins. Scandinavian Journal Immunology, v.53, p.218-226, 2001

SOBESTIANSKY, J. et al. Pneumonia enzoótica. In: Clínica e patologia suína. 2.ed. Goiânia, Goiás: Art 3 Impressos Especiais, 1999. p.359.

SOBESTIANSKY, J. et al. Estudos ecopatológicos das doenças respiratórias dos suínos: prevalência e impacto econômico em sistemas de produção dos estados de SC, RS e PR. Concórdia, SC: EMBRAPA-CNPSA, 2001. p.6. (Comunicado Técnico 287).

THACKER, E.L. et al. Mycoplasma hyopneumoniae potentiation of porcine reproductive and respiratory syndrome 
virus-induced pneumonia. Journal Clinical of Microbiology, v.37, p.620-627, 1999.

THACKER, E.L. et al. Evaluation of local and systemic immune responses induced by intramuscular injection of a Mycoplasma hyopneumoniae bacterin to pigs. American Journal of Veterinary Research, v.61, p.1384-1389, 2000.

TORTORA, G.J. et al. Mecanismos microbianos de patogenicidade. In: - Microbiologia. 6.ed. Porto Alegre, RS: Artmed, 2000. p.421-440.

VICCA J. et al. Evaluation of virulence of Mycoplasma hyopneumoniae field isolates. Veterinary Microbiology, v.97, p.177-190, 2003.

WALKER, R.L. Mollicutes. In: HIRSH, D.C., ZEE, Y.C. Microbiologia veterinária. Rio de Janeiro: Guanabara Koogan, 2003. p.155-162.
WILTON, J.L. et al. Reiterated repeat region variability in the ciliary adhesion gene of Mycoplasma hyopneumoniae. Microbiology, v.144, p.1931-1943, 1998.

ZHANG, Q. et al. Microtiter plate adherence assay and receptor analogs for Mycoplasma hyopneumoniae. Infection and Immunity, v.62, p.1013-1019, 1994.

ZHANG, Q. et al. Identification and characterization of a Mycoplasma hyopneumoniae adhesin. Infection and Immunity, v.63, p.1013-1019, 1995.

ZIELINSKI, G.C.; ROSS, F.R. Adherence of Mycoplasma hyopneumoniae to porcine ciliated respiratory tract cells. American Journal of Veterinary Research, v.54, p.12621269, 1993. 